\title{
O ESPAÇO VAZIO. REFLEXÕES SOBRE A FUNÇÃO DO VAZIO NA CURA PSICANALÍTICA E NA ARTE
}

Giselle Falbo

Psicanalista; Professora adjunta da Universidade Federal Fluminense; doutora em Teoria Psicanalítica /UFRJ.

RESUMO: Este trabalho tem por objetivo discutir e situar a função do vazio na obra de arte, a partir das teorizações de Melanie Klein e Jacques Lacan. Confrontando a posição de Klein em relação ao processo de criação — extraída da análise que faz de dois fragmentos literários — com a teorização sobre o objeto tal como formulada por Lacan nos anos de 1959-60, nossa proposta é discernir a operação de simbolização inerente à arte. Entendemos que este processo possibilita a passagem da desorganização suscitada pela presentificação do buraco - manifesta clinicamente pela angústia — à sua metaforização como falta através da qual se inscreve o vazio, estabelecendo-o em sua porção criativa.

Palavras-chave: Psicanálise, arte, criação, sublimação.

ABSTRACT: The empty space. Reflections on the function of the emptiness in the psychoanalytic cure and art. This study aims at discussing and situating the role of the emptiness in the work of art, from the theorization of Melanie Klein and Lacan. Confronting Klein's position in relation to the process of creation - extracted from the analysis of two literary fragments - with the theorization of the object as proposed by Lacan in the years 1959-60, our proposal is to distinguish the symbolization inherent to art. We understand that this process enables the passage of disorganization suggested by the presence of the "hole" (ontogenic absence) — clinically manifested by anguish - to its metaphorization as absence through which emptiness is inscribed, settled in its creative portion.

Keywords: Psychoanalysis, art, creation, sublimation. 
“Seja qual for o caminho que eu escolher, um poeta já passou por ele antes de mim.” (Freud)

$\mathrm{N}$ o percurso que a psicanálise escreve desde sua fundação, com Sigmund Freud, na virada que inaugura o século XX, a arte foi recorrentemente utilizada como instrumento para fazer avançar questões cruciais para a psicanálise. Como obra da ficção portadora, portanto, de um savoir-faire que coloca em cena a dimensão simbólica, a arte propicia condições para que o psicanalista possa examinar fenômenos que, de outro modo, seriam dificilmente apreendidos e trabalhados. É o que ocorre, por exemplo, na vivência do estranho: fugidia tanto na vida cotidiana quanto na clínica, mas apreensível através dos textos literários e de outras produções artísticas.

Como decorrência desta característica da arte, ela teve sempre muito a ensinar ao psicanalista. E inúmeras foram as suas incidências em momentos decisivos para a reflexão e teorização das questões suscitadas pela experiência clínica, como atestam os escritos de Freud — Delírios e sonhos na Gradiva de Jensen (1906/1980), Escritores criativos e devaneio (1908/1980), Leonardo da Vinci e uma lembrança de sua infância (1910/1980), O estranho (1919/1980), Dostoievski e o parricídio (1928/1980), entre outros - bem como o ensino de Lacan, nos estudos sobre Hamlet, a Trilogia Tebana de Sófocles (1959-60/1997) e a análise dos escritos de Joyce (197576/2007) e Gide (1958/1998), apenas para citar alguns. Dentre as contribuições que a reflexão a propósito da arte nos aportou, recortamos aqui a discussão, caríssima para o nosso campo, acerca do estatuto do objeto em psicanálise, tema que ganhou leituras diversas, a partir das diferentes escolas da psicanálise, que refletem posicionamentos distintos em relação ao lugar concedido ao buraco, ao vazio e à falta.

Neste artigo, nos restringiremos a contrapor - através do estudo do caso de Ruth Kjär, trabalhado por Melanie Klein (1929) e mais tarde discutido por Lacan (1959-60/1997) — a posição kleiniana referente ao objeto na criação artística à teorização de Lacan sobre o tema. Deste modo, pretendemos destacar as contribuições do pensamento lacaniano para a reflexão sobre a dimensão criativa da lacuna, ou melhor, sobre a operação necessária para que o vazio possa se constituir como espaço aberto ao surgimento do novo.

\section{CRIAÇÃO E SENTIMENTO DE CULPA NA TEORIA DE MELANIE KLEIN}

Melanie Klein, uma das psicanalistas mais expressivas da Escola Inglesa, apresenta de modo bastante elucidativo o seu pensamento sobre a arte no artigo Situações de ansiedade infantil refletidas numa obra de arte e no impulso criador (1929). O texto se divide em duas partes: na primeira discute-se, através da análise do material psico- 
lógico subjacente à ópera $A$ palavra mágica, ${ }^{1}$ de Ravel, a fase do desenvolvimento cujo conteúdo é a agressão ao corpo da mãe; a segunda situa — por meio da discussão do caso da pintora Ruth Kjär - a reparação como o operador que viabiliza a superação das angústias geradas pela agressividade infantil dirigida ao objeto materno. Valendo-se destes dois fragmentos literários, a psicanalista objetiva demonstrar que por trás das diferenças marcadas nas tensões edipianas, vividas de modos distintos pelos meninos e pelas meninas, subjaz uma mesma angústia, mais primitiva que a referida à castração — nos meninos - e a perda do objeto de amor — nas meninas.

De acordo com Klein, a saga do menino que enfrenta a ira dos terríveis objetos que ganham vida — orquestrada por Ravel — ilustra de modo exemplar a angústia engendrada pelos ataques sádicos ao corpo da mãe, os quais respondem à frustração oral, que acirra o sadismo, e converte a mãe "boa", indulgente, em mãe "má". Essa agressividade produz, como contrapartida, uma angústia avassaladora, correlativa à fantasia do corpo materno destruído que, em represália, se voltaria contra o sujeito, punindo-o. Adiantamos que a situação enfocada por Klein pode ser lida - à luz da teoria de Lacan — como o embate especular inerente à relação dual com o outro, o semelhante; situação na qual o sujeito fica à mercê da tensão mortífera expressa pela lógica imaginária: ou eu ou você.

Na perspectiva do desenvolvimento ontogênico de Klein, o sadismo é superado quando o sujeito atinge o nível genital, por força da compaixão e da simpatia. Situando a saída para o sadismo no nível do amor, Klein mantém a solução do conflito no plano narcísico e, portanto, imaginário, como indicam os significantes por ela recortados: "simpatia" e "compaixão". Na estória narrada pela ópera, é o compadecimento do menino ao socorrer o esquilo ferido por seus ataques de fúria que transforma o mundo, antes hostil, em um lugar amistoso. Ou seja, é a identificação imaginária com o outro — o esquilo — que constitui a moldura que faz barra à agressividade.

\section{O ESPAÇO VAZIO NO CASO DE RUTH KAJÄR}

A articulação entre a superação da angústia e a reparação é apresentada, na segunda parte de seu escrito, através da reflexão sobre o processo criativo. Remetendo-nos ao artigo O espaço vazio, Klein discute a dissolução da angústia no caso de Ruth Kajär, originalmente narrado por Karin Mikailes. Versa a estória que Ruth, uma moça "linda, rica e independente" (KLEIN, 1929, p.289), vez por outra era acometida por acessos de depressão profunda, ocasião em que se queixava de ser habitada por uma lacuna, um descontentamento angustiante por ela nomeado "espaço vazio" - expressão que alude a algo que ela nunca fora capaz

\footnotetext{
${ }^{1}$ Em alemão, Das Zauberwort.
} 
de preencher. Por força dos acontecimentos, Ruth se casa e, por algum tempo, as coisas parecem se ajeitar. No entanto, esta situação de aparente tranquilidade não perdura por muito tempo, e logo os acessos de melancolia retornam.

Por uma razão que não é bem esclarecida na narrativa do caso, as paredes da sala da casa em que Ruth mora são cobertas por quadros confeccionados pelo cunhado, que é um pintor reconhecido. Ocorre que, pouco antes do Natal, o cunhado vende uma das telas que forrava a parede, deixando em seu lugar um buraco: um espaço vazio na parede que parece funcionar como precipitador de novas crises melancólicas. Tragada por este buraco que zomba "horrivelmente dela” (KLEIN, 1929, p.290) e que parece coincidir com o vazio que a habita, a moça cai num estado de profunda tristeza. Todavia, de maneira surpreendente, Ruth sai deste estado desolador quando, fazendo do buraco em uma tela, decide dar algumas pinceladas, construindo alguma coisa no lugar vazio que adquirira, inicialmente, um valor cristalizante. Daí surge uma “obra de arte”, por meio da qual o vazio é preenchido e a angústia, aplacada.

Para Klein, esta estória ilustra de modo exemplar a estrutura do processo de criação. Em sua doutrina, este “espaço vazio” é o lugar onde se situa originalmente o corpo materno, objeto originário que estaria concernido em todo e qualquer modo de sublimação. A motivação para a criação residiria na tentativa de reparar o corpo da mãe, despedaçado pelos ataques agressivos da criança. Visto que o bebê entra na posição depressiva e se defronta com o sentimento de ter destruído onipotentemente a sua mãe, a culpa e o desespero por tê-la perdido despertam o desejo de restaurá-la, recriando-a no intuito de recuperá-la interna e externamente. Para a psicanalista inglesa, tal impulso constitui a base das atividades criativas, enraizadas na culpa e no desejo de restabelecer e recriar a felicidade perdida, seus objetos e a harmonia de seu mundo interno.

As fantasias e as atividades reparadoras - tais como a arte — são lidas como modos de enfrentar a angústia provocada pelo confronto com o buraco. Ou seja, são maneiras de resgatar o objeto imaginariamente destruído pela agressividade infantil, dando tratamento para a devastação frente à qual o sujeito sucumbe. A recuperação do objeto através do procedimento de reparação é considerada, na doutrina kleiniana, tarefa primordial para se empreender a desmontagem da crença na onipotência infantil, tornando o ódio infantil menos assustador.

De acordo com Klein, a fonte do prazer e da beleza pode ser equiparada, no inconsciente, ao seio amado da mãe. Todos os dons multiformes da natureza são igualados àquilo que a criança recebeu, no passado, da mãe. Mas esta "mãe boa" comporta também uma face sombria, obscura. A mãe nem sempre é satisfatória, e é igualmente sentida, com frequência, como sendo pouco generosa e frustradora. Assim, os sentimentos de prazer e desprazer derivam, em primeira instância, desta única e mesma fonte: a "mãe, que não apenas mitigou os tormentos da 
fome, mas também satisfez as nossas necessidades emocionais e aliviou em nós a ansiedade” (KLEIN \& RIVIERE, 1975, p.152).

Segundo Klein, a formação do superego dá-se precocemente e acompanha o início das tendências edipianas. Assim, o ego frágil e infantil fica submetido à influência do sadismo da instância superegoica. Como decorrência, quando os objetos são introjetados, a agressão a eles dirigida provoca o temor de ser atacado de forma análoga pelos objetos internalizados, gerando angústia. E é tarefa da análise descobrir, por completo, estas situações de angústia até suas camadas mais profundas, revelando aquilo que, nos termos freudianos, é designado "cena primária” (KLEIN, 1929, p.286). Na perspectiva de Klein, os temores próprios ao Édipo - nas meninas, o medo da perda do objeto; nos meninos, a castração - estão ligados a uma angústia ainda mais precoce: a agressão ao corpo da mãe. Esta agressividade é correlativa ao apogeu da fase sádica, posição que implica um combate que também inclui o pai — presentificado pelo pênis suposto existir dentro do ventre materno. Esta reunião pai-mãe confere intensidade especial à situação de perigo, posto que estes pais unidos seriam agressores extremamente cruéis e temidos pela criança.

No lugar do vazio que corresponde à ausência estrutural do objeto das satisfações humanas — o objeto desde sempre perdido - a teorização de Klein coloca a mãe, considerada como objeto original a ser recuperado pelo esforço de criação. Como decorrência desta concepção de objeto, a criação fica ligada à falta visada no registro imaginário: o dano imaginário. E o sentimento de culpa é alçado à posição de motor fundamental para a criatividade.

Não escapa, contudo, à aguda escuta clínica de Klein, que, embora o desejo de reparação — suposto intensamente ligado à pessoa amada e à associação em torno de sua morte - possa expressar-se de maneira criadora e construtiva, nos casos em que o sentimento de culpa é muito intenso, ele produz justamente o efeito contrário, inibindo as atividades e interesses produtivos, o que indica a insuficiência de sua teorização ao pretender responder às questões postas pelo processo de criação pelo viés de sua articulação ao supereu. Destacamos que, mesmo considerando-as insatisfatórias, Lacan reconhece, na teorização kleiniana, o mérito de haver situado a topologia na qual se desdobram os fenômenos da criação.

Tomando o real como o eixo que orienta a ética da psicanálise, Lacan (195960/1997) recoloca o problema posto pela introdução do novo, a criação, em outros termos. Enquanto, para Klein, a "palavra mágica” é mamãe — tal como pronunciada pelo protagonista da ópera de Ravel — Lacan segue fiel à formulação freudiana sobre a ausência estrutural do objeto de satisfação, situando no coração da economia psíquica o objeto desde sempre perdido: das Ding. Destacando uma dimensão do objeto diversa da engendrada pelo anseio por reciprocidade - re- 
ciprocidade que, em toda relação sujeito-objeto, se estabelece sobre o império da identificação - ele nos oferece outra interpretação para o processo de criação, indicando-o como saída possível para o embate imaginário que caracteriza nossa relação com o próximo.

\section{DO BURACO QUE HORRORIZA À FECUNDIDADE DO VAZIO}

Através da explanação teórica apresentada por Klein sobre o processo de criação, vimos que a autora situa a arte e o final de análise no plano da reparação engendrada pela identificação do menino com seu semelhante, o esquilo que fora ferido por seus ataques de fúria. Na perspectiva kleiniana, é a identificação o que constitui a moldura que faz obstáculo à agressividade. Retomando Freud, em O mal-estar na civilização (1930/1980), Lacan afirma — através da discussão dos paradoxos determinados pelo mandamento do amor ao próximo - que a análise deve visar outra dimensão do objeto, distinta do plano em que se edificam os objetos libidinais, narcísicos.

Contrapondo-se à orientação traçada por Klein, Lacan (1959-60/1997) nos mostra a falácia da pacificação erigida pelo logradouro das identificações, nos advertindo para o que há de desumano no imperativo "amarás a teu próximo como a ti mesmo", mandamento que se assenta justamente na redução do próximo à sua vertente especular. De acordo com o psicanalista francês, somos solidários com tudo aquilo que repousa sobre a imagem do outro como nosso semelhante, "na similitude que temos com o nosso eu e com tudo o que se situa no registro imaginário” (LACAN, 1959-60/1997, p.239). Tal solidariedade, como explicita Freud (1930/1980), abarca não apenas o semelhante — o eu ideal — mas também o ideal do eu, ambos contidos no campo circunscrito pelo amor narcísico. Nos termos de Freud:

\footnotetext{
"Se amo uma pessoa, ela tem de merecer meu amor de alguma maneira. (...) Ela merecerá meu amor, se for de tal modo semelhante a mim, em aspectos importantes, que eu me possa amar nela; merecê-lo-á também, se for de tal modo mais perfeita do que eu, que nela eu possa amar o meu ideal de meu próprio eu.” (FREUD, 1930/1980, p.131)
}

Esta compaixão, contudo, logo rateia quando o outro surge como desigual, posto que, como dizia o poeta, "narciso acha feio o que não é espelho”. Este estranho com o qual eu não me identifico é tido como indigno de meu amor, como observa Freud com veemência: "honestamente, tenho de confessar que ele possui mais direito à minha hostilidade e, até mesmo, meu ódio” (1930/1980, p.131) O problema é, portanto, como amar o próximo quando ele surge como dessemelhante. Este impasse deve-se, conforme desenvolveremos adiante, à im- 
possibilidade de se simbolizar a diferença no nível da relação dual. Neste registro, a disparidade é sempre interpretada como mais ou como menos, maior ou menor. Nestas condições, quando o outro se apresenta supostamente inteiro e alheio ao furo, o sujeito resta defeituoso ou faltoso. Isto porque, a imagem que forja um eu ideal escamoteia e recobre a falha estrutural, inerente à condição humana.

No nível especular, as imagens fascinam e enganam, não nos deixando perceber que, embora belas, são ocas. Neste plano, o vazio sobre o qual se edificam o mundo e seus objetos - e consequentemente as relações de objeto - é sempre velado pela imagem do outro total, deslumbrante e alheio ao furo. Destacamos que, se Lacan insiste em ressaltar os engodos do semelhante, é porque dele nascem os desconhecimentos que nos definem como um eu. A suposta integridade do eu, fornecida pelo registro especular, é precária e se esfacela na medida em que avançamos em direção ao vazio central, sobre o qual a imagem se apoia. Por esta razão, ao modo dos porcos espinhos de Schopenhauer, na proporção em que prosseguimos rumo ao gozo, o corpo do outro se despedaça. Em contrapartida, se nos afastamos do contato com o outro, padecemos da falta de calor humano. Por esta razão faz-se necessário encontrar a "distância intermediária" (FREUD, 1921/1980, p.128) que nos possibilita tolerar a coexistência com o próximo.

Com o objetivo de delinear uma alternativa ao embate mortal configurado pela relação dual, Lacan (1959-60/1997) nos indica — através da discussão sobre a criação - uma trilha por meio da qual se delineia um litoral diverso da barreira edificada pelo mundo dos bens. Sua argumentação sobre a sublimação pretende comprovar que a chave da criação, assim como da cura psicanalítica, está em lugar diverso ao da identificação: encontra-se no corte estabelecido pelo significante esvaziado de sentido - termo que indica, para além da imagem, o vazio que o sustenta. E como metáfora da operação que extrai um significante da cadeia, isolando-o como único para modelá-lo de modo que o vazio possa ser cernido, o psicanalista toma o ato de criação tal como realizado pelo artista. Nota-se que este significante único e desarticulado da cadeia será nomeado letra em suas construções teóricas posteriores: traço que constitui litoral entre planos radicalmente distintos.

No contexto do Seminário sobre a ética, a discussão a propósito da criação fornece elementos para que se possa discernir o objeto estruturado a partir da imagem do semelhante, de das Ding: a Coisa freudiana, porção não recoberta pela imagem que coloca em cena o que será nomeado, posteriormente, objeto a. Apesar de a articulação significante empreendida no processo de sublimação visar a Coisa, esta, como vazio situado no âmago da economia libidinal, não pode se fazer representar senão por outra coisa. Por este motivo, muito embora a operação de sublimação seja sempre concernente à porção que escapa à cobertura 
oferecida pela imagem, o processo de criação será necessariamente indissociável de suas elaborações imaginárias.

Para Lacan (1959-60/1997), a sublimação corresponde à outra face da exploração das raízes do sentimento ético, que, por um lado, se apresenta sob a forma de interdições — de consciência moral — e, por outro, como criação de valores (FALBO, 2003, p.6). Todos os modos de sublimação — religião, arte e ciência - visam o vazio situado no seio da economia psíquica e seguem a fórmula geral: "elevar um objeto qualquer à dignidade da Coisa" (LACAN, 1959-60/1997, p.140-141). Esta primeira formulação lacaniana, no entanto, não nos permite estabelecer distinção alguma entre as miragens confeccionadas pelos artistas e as forjadas pelos moralistas, os cientistas e os fabricantes de bens de consumo; criações estas que, por nos iludirem a respeito da verdadeira "natureza" de das Ding, nos permitem nelas encontrar alguma felicidade.

Dentre os diferentes modos de sublimação, Lacan (1959-60/1997) designa, contudo, um lugar distinto para a arte. Enquanto a ciência foraclui e a religião nos mantém afastados do vazio central em torno do qual giram os representantes da representação, a arte opera seu milagre de modo radicalmente diferente. Valendose do fascínio e da atração promovidos pela imagem, a arte é destacada como a única forma de sublimação consagrada à edificação de cadeias significantes não devotadas à lei do engodo. É importante sublinhar, que enquanto o princípio do prazer regula o aparelho psíquico através do engano - já que visa a identidade de percepção e a busca de satisfação através do signo — - a arte opera seu milagre em direção oposta. Destacamos que, embora ficção, o que a arte movimenta não se rege pela lei do engodo ou da farsa. A arte, assim como a psicanálise, não se orienta pelo campo dos ideais, mas pelo real: o que não engana.

Por esta estreita afinidade com o real, a arte por vezes coloca em cena modos de satisfação situados para além do prazer, satisfações que se aproximam muito da angústia, tal como destacado por Freud no texto O estranho (1919/1980), pela análise do conto de Hoffman, O homem de areia. Se na arte, assim como na angústia, é sempre do objeto a que se trata, não deveria nos surpreender que a arte, mesmo dando tratamento a este real, possa estar estreitamente ligada ao mal-estar desencadeado pela angústia e tenha como tema o horror, a violência e o escatológico. Este fato se evidencia na obra de grandes artistas: nos corpos despedaçados de Bosch, nos horrores da guerra de Goya ou na Guernica de Picasso, para citar apenas os mais conhecidos.

Ao promover a reordenação significante, a arte faz aparecer, para além da imagem, o vazio da Coisa. O que é visado na arte não é, portanto, a imagem retratada, mas a obra como significante que delimita o vazio que o estabelece como linguagem. Se a arte imita, é justamente para afirmar a face do objeto que aponta para a ausência que o institui como significante. De onde se conclui 
que nos simulacros construídos pela arte o que está em jogo é muito mais a sua materialidade, o significante despojado de sentido, do que a imagem. Tal como estabelecido no Seminário Os quatro conceitos fundamentais da psicanálise (LACAN, 1964/1990), por meio deste esvaziamento produzido pela operação artística o que se mira não é a dimensão fálica do objeto, mas o a indicado mais além vetor que concerne ao gozo, à satisfação pulsional.

Neste sentido, a arte não pretende falsificar o real ou a realidade. Afirmandose como representação, a arte sustenta a lacuna necessária para que a linguagem possa operar como discurso. Estabelecendo-se como imitação, a arte dá tratamento ao real posto que, ao fazer valer o intervalo - o ponto vazio que estrutura - ela estabelece o corte que distancia, ou melhor, media nossa relação com o Outro. Este oco recortado no interior da estrutura é o ponto que garante a abertura para que se possa acolher a diferença e a singularidade. Deste modo, a arte se faz atividade sempre necessária, por fazer contraponto aos discursos que estabelecem os modos de poder e de gozo que regulam os laços sociais.

Nisto reside seu valor civilizatório, uma vez que este decantar de sentido, este esvaziamento de saber, é correlativo à terraplanagem de gozo que possibilita a passagem da proximidade insuportável do Nebermensh à condição de cadeia estruturada, discurso. Como única articulação significante capaz de salvaguardar o vazio da Coisa, a arte nos afirma a inconsistência do próximo que viabiliza a construção de laços sociais.

Tecidas as considerações sobre a arte e o processo de criação a partir da teoria lacaniana, gostaríamos de lembrar que a reflexão de Lacan sobre o tema não pretende ser definitiva e tampouco tem a intenção de responder por todos os modos da arte, tal como se evidencia, por exemplo, neste comentário que ele faz sobre suas proposições a propósito da pintura: "Se considerarmos todas as modulações que impuseram à pintura as variações, no curso do tempo, da estruturação subjetivante, é claro que nenhuma fórmula permite ajuntar essas visadas, esses ardis, esses truques infinitamente diversos" (LACAN, 1964/1990, p.109). Ainda que tenha uma posição bastante sólida em relação à criação e à satisfação fruída através da obra de arte, em nenhum momento de seu ensino Lacan pretendeu construir um saber que possa ser aproximado da teoria ou crítica da arte. Ainda que afeito às artes, em seus seminários e escritos, as considerações sobre o tema estão necessariamente devotadas a auxiliar a reflexão da experiência clínica e seus impasses.

\section{PARA CONCLUIR: O QUE A ARTE ENSINA PARA A PSICANÁLISE?}

Através das reflexões sobre a arte recortadas de 0 Seminário 7, podemos concluir que o estudo da sublimação se insere em uma perspectiva ético-estética que coloca em cena a economia do gozo - economia do prazer e da satisfação. 
Pelo exame da criação artística depreende-se que os rodeios estabelecidos pela cadeia de significantes - exigência de trabalho requerido pela insistência das pulsões - nem sempre se realiza no sentido de regular a passagem que reúne o que se organiza no âmbito do princípio do prazer ao que se propõe como estrutura de realidade. Em outras palavras, o que a arte nos ensina é que no tratamento dispensado ao real pelo simbólico, nem tudo funciona no sentido de forçar a conformação às normas vigentes. Há igualmente rodeios e obstáculos que se organizam para fazer aparecer o vazio que institui a estrutura - como linguagem e como laço social.

Por meio de sua aguda escuta clínica, Lacan nos mostra que a dimensão do objeto operativo em análise, e que produz o corte que viabiliza a saída do círculo vicioso imposto pela repetição, é uma noção funcional de natureza radicalmente distinta daquela que concebe o objeto como puro e simples correspondente do sujeito e de qualquer outro associado às suas demandas. No tratamento psicanalítico, portanto, o que possibilita mudanças efetivas não é propriamente o amor, mas o que se decanta, pouco a pouco, do laço transferencial: o objeto reduzido ao real. Objeto que, em decorrência da dificuldade de simbolização da falta, emerge de forma assustadora sobre o fundo de uma realidade angustiante. E que em um momento lógico posterior, decantado da consistência que lhe conferia imaginariamente a fantasia, tem sua realidade desvelada pela experiência clínica: uma cavidade oca e desobstruída, espaço aberto ao novo e à criação.

Para se chegar ao cerne do objeto, destarte, a análise precisa orientar-se em direção oposta à consistência que a fantasia propicia. Se por um lado o fantasma - como resposta ao que há de enigmático e aterrorizante no desejo do Outro edifica uma cobertura que protege o sujeito da angústia, por outro, ele o aliena na posição de objeto. E é sobre este ponto que incide a crítica que Lacan dirige à teorização de Klein a partir da reflexão sobre a arte e o processo de criação.

Orientando-se pelo real e não pelo ideal, Lacan indica que a experiência ética em questão na psicanálise não se limita ao aspecto de resignar-se a perder o que não tem jeito, ou seja, não está unicamente ligada à figura obscena do supereu e à exploração de seus paradoxos. A experiência em questão na análise é também aquela que propõe a ascese expressa pela máxima freudiana $W_{0}$ Es war, Soll Ich werden (LACAN, 1959-60/1997, p.16), e que pode ser traduzida por: onde o isso era, o sujeito há de advir. Quanto mais o eu se interroga sobre seu desejo, e consequentemente progride na experiência analítica, mais esta pergunta vai se colocando no lugar dos estranhos imperativos, paradoxais e cruéis, que lhe eram impostos pela experiência mórbida. Deste modo, a pergunta sobre o desejo vai constituindo a barra que limita o gozo.

Pelo que foi exposto, depreende-se que a discussão em torno da sublimação, além de fornecer elementos essenciais para se pensar a arte e a criação através 
da psicanálise, comporta uma dimensão clínica importantíssima no que concerne à intervenção do analista: o seu ato deverá se dirigir ao desvelamento da realidade fictícia da fantasia, posto que o advento do novo, a quebra do círculo compulsivo da repetição, não se realiza pela elucidação das fantasias como revelação do saber inconsciente. Este trabalho, tal como escreve Freud (1920/1980), é insuficiente. De onde podemos concluir que a interpretação no tratamento não deve se endereçar a desvendar os sentidos ocultos pelo saber inconsciente, a fazer vacilar suas significações.

Como tratamento dado ao real pela palavra, a intervenção do analista não deve favorecer o recobrimento dado pelo fantasma. Isto porque, operando em nome de um saber, ao nomear o objeto, a interpretação favorece a consolidação da fantasia. O analista orienta-se, portanto, em outra direção: aquela que torna presente o objeto designado como falha, equívoco que deixa entrever a fantasia como ficção. Como corte, o ato analítico não incide sobre a cadeia articulada, mas no ponto em que ela falha, fazendo emergir o objeto. Ele não opera na vertente da significação, da cadeia articulada de pensamentos inconscientes, mas em direção ao que, no inconsciente, é indecifrável e que precisa ser cifrado. O sentido da análise não é, por conseguinte, a significação, mas o real (LACAN, 1974).

Para finalizar podemos dizer, com Lacan (1974), que no tratamento psicanalítico a intervenção do analista deve incidir ao modo do ready-made de Duchamp, ou seja, como um ato que traz à tona o essencial do que há no jogo de palavras: o nonsense que não alimente o sintoma de sentido. Só assim o objeto se reduz ao real, a algo que se separa e não mais se ergue sobre o fundo de angústia terrificante. Este objeto é o que se destaca ao longo da cura para que, no limite da pesquisa analítica, o sujeito possa perceber que não há razão alguma para se ter medo dele.

Recebido em 24/9/2008. Aprovado em 30/11/2008. 


\section{REFERÊNCIĀS}

FALBO, G. (2003) Para que serve? Quanto vale? Reflexões da psicanálise sobre a crise da arte. Tese de doutorado defendida no Programa de Pós-Graduação em Teoria Psicanalítica da UFRJ.

FREUD, S. (1980) Edição standard brasileira das obras psicológicas completas de Sigmund Freud, Rio de Janeiro: Imago.

(1906) Delírios e sonhos na "Gradiva" de Jensen, v. IX, p.17-104.

(1908) Escritores criativos e devaneio, v. IX, p. 149-162.

(1910) Leonardo da Vinci e uma lembrança de sua infância, v. XI, p.59-126.

(1919) O estranho, v. XVII, p. 275-314.

(1920) Além do princípio do prazer, v. XVIII, p.17-90.

(1921) Psicologia de grupo e análise do ego, v. XVIII, p.91-184.

(1928) Dostoievski e o parricídio, v. XXI, p.205-224.

(1930) O mal-estar na civilização, v. XXI, p.81-178.

KLEIN, M. (1929) "Situações de ansiedade infantil refletidas numa obra de arte e no impulso criador” in Psicanálise da criança. São Paulo: Editora Mestre Jou, 1975.

\& RIVIERE, J. (1975) Amor, ódio e reparação. Rio de Janeiro: Imago Editora.

LACAN, J. (1959-60/1997) O Seminário Livro 7, A ética da psicanálise. Rio de Janeiro: Jorge Zahar.

(1964/1990) O Seminário Livro 11, Os quatro conceitos fundamentais da psicanálise. Rio de Janeiro: Jorge Zahar.

. (1974) A terceira. Conferência pronunciada em Roma no $7^{\circ}$ Congresso da École Freudienne de Paris, tradução inédita da EBP.

Giselle Falbo

gifalbo@centroin.com.br 